\title{
La ratificación de la CEDAW como hito en la lucha por los derechos de las mujeres en el Perú(*)(**)
}

\author{
The ratification of CEDAW as a milestone in the struggle for women's rights \\ in Peru
}

Marcela Huaita Alegre ${ }^{(* *)}$

Perú - Pontificia Universidad Católica del Perú

Gissela Cornejo Castellano( ${ }^{(* * * x)}$

Perú - Pontificia Universidad Católica del Perú

\begin{abstract}
Resumen: En el Perú, la ratificación de la Convención para la eliminación de toda forma de discriminación contra la mujer (CEDAW), dada a inicios de los 80, se enmarca en un proceso de transición no sólo política sino entre dos generaciones de mujeres activistas. Una de ellas es el grupo de mujeres profesionales, que luego de la conquista del voto han sido llamadas a participar en la vida política, como Matilde Pérez Palacio, primera abogada PUCP y luego diputada por Acción Popular, y otras que han fundado organizaciones no gubernamentales de protección a la infancia y a la madre abandonada como María Vita de Álvarez. Destacadas profesionales vinculadas siempre al Consejo Nacional de Mujeres, creado en 1923, como Sara Pérez Palacio, Olga Paredes Lañas de De Olarte y muchas más. Esta generación de mujeres, entre las cuales encontramos un importante contingente de abogadas PUCP, es a la que les toca dar opinión positiva para la ratificación de la CEDAW, lo cual hacen desde sus instituciones, pero sin acallar la crítica que les merece la situación de postergación que vivían las mujeres. Por otro lado, una siguiente generación de mujeres activistas de la segunda ola del movimiento feminista peruano es quien reivindicará la CEDAW años después, y a las que les tocará en su momento asumir la responsabilidad pública y política, como les tocó a la generación que las antecedió.
\end{abstract}

Palabras claves: Convención para la Eliminación de toda forma de Discriminación contra la Mujer - CEDAW - Consejo Nacional de Mujeres - Derechos Humanos de las Mujeres - Abogadas PUCP

Abstract: In Peru, the ratification of "The Convention on the Elimination of all forms of Discrimination Against Women (CEDAW)" that takes place in the beginnings of

$\left(^{*}\right) \quad$ Nota del Editor: este artículo fue recibido el 8 de octubre de 2019 y su publicación fue aprobada el 28 de octubre de 2019.

${ }^{* *}$ Una primera versión de este artículo fue presentado en la I Jornada de Estudios de Género y las Mujeres en la Historia del Perú. Lima, 11 y 12 de octubre 2018.

$\left.{ }^{(* *}\right)$ Abogada (PUCP, 1991), magíster en Estudios Legales Internacionales por el Washington College of Law de la American University (LLM, 1997), egresada del Doctorado de Derecho (PUCP, 2012). Docente PUCP en Facultad de Derecho, y Escuela de Post Grado (Maestrías: Estudios en Género, Derechos Humanos). Investigadora asociada al IDEHPUCP. Consultora internacional, experta en temas de género, derechos humanos y políticas públicas. Ha ocupado altos cargos en el Poder Ejecutivo, siendo ministra del Ministerio de la Mujer y Poblaciones Vulnerables (2015-2016), así como Presidenta de la Comisión Interamericana de Mujeres (CIM/ OEA, 2016), y desde el 2018 miembro del Comité de Expertas del MESECVI/OEA. Contacto: mhuaita@pucp.edu.pe

$\left(^{* * * *}\right)$ Bachiller de Comunicación para el Desarrollo de la PUCP (2018). Con experiencia en proyectos de comunicación para el desarrollo e investigación sobre género y diversidad sexual. Sus áreas de interés son estudios de género, diversidad y comunicación política. Fue miembro del grupo de investigación en el Grupo de Investigación de Políticas Públicas y Gestión Pública. Sección de Políticas Públicas para la Diversidad Sexual (DISEX). Coautora de la publicación: "Igualdad para construir democracia. Análisis de las candidaturas LGTBI en los procesos electorales 2006 al 2016". Actualmente labora en el área de prensa del Consorcio de Investigación Económica y Social (CIES). 
the 80 's is part of a transition process not only in the political front, but also between two generations of women activists. One of which was represented by a group of professionals called to take an active role in the political front, women such as former deputy and first PUCP woman lawyer, Matilde Pérez Palacio as well as other founders of NGO's focused on child protection and abandoned mothers, such as María Vita de Alvarez. Prestigious group of professionals linked to "Consejo Nacional de Mujeres", founded in 1923, such as Sara Pérez Palacio, or Olga Paredes Lañas de De Olarte, just to name a few. This is the generation of women called to give a positive outlook towards the ratification of CEDAW -among which we find an important contingent of PUCP women lawyers, which they all do from their institutions by voicing the criticism about the difficult situation in which women lived then. Conversely, the next generation of women activists who represent the second wave of the Peruvian feminist movement are the ones called, years later, to claim the CEDAW. Moreover, this is the generation called to take a stand and assume now the political and public responsibility, just as the previous generation did.

Keywords: Convention on the Elimination of all forms of Discrimination against Women - CEDAW - National Council of Women - Women's Human Rights - Pucp Women Lawyers

\section{Introduc ción}

La Convención sobre todas las formas de discriminación contra la mujer (CEDAW, por sus siglas en inglés) "es un instrumento de carácter internacional que precisa los detalles de la discriminación contra las mujeres y establece los lineamientos necesarios para erradicarla" (Cátedra Unesco México s.f). La CEDAW, reconocida como la "Convención de las Mujeres", es desarrollada en 30 artículos organizados en seis partes, en los cuales define principalmente cuáles son los actos que constituyen discriminación contra la mujer y establece la obligación estatal de desarrollar leyes, políticas públicas y programas para eliminar la discriminación. Las áreas que aborda van desde el ámbito familiar hasta la vida política y pública, pasando por esferas como educación, salud, mundo rural, prestaciones económicas y sociales, entre otras.

"La Convención está compuesta de una serie de normas y obligaciones aceptadas por todos y todas. Estas normas básicasdenominadas también derechos humanos-establecen derechos y libertades mínimas que los gobiernos deben cumplir. Acompañan a estos derechos la obligación de los gobiernos y los individuos de no infringir los derechos paralelos de los demás. Estas normas son interdependientes e indivisibles; no es posible garantizar algunos derechos a costa de otros" (Sistema de Naciones Unidas de Panamá, s.f).

La CEDAW, como todo tratado internacional de derechos humanos, es parte del ordenamiento interno peruano y es obligatoria la incorporación de sus estándares tanto en la justicia ordinaria como la constitucional, así como en todas las instancias estatales: nacional, regional, provincial y municipal. El Estado peruano debe estar comprometido a realizar los derechos allí contenidos, y a garantizar su ejercicio y goce para toda mujer a lo largo de su ciclo de vida.

Habiéndose cumplido más de 35 años de su vigencia en nuestro país, resulta interesante mirar en retrospectiva y analizar el contexto en el que se da su ratificación, dado que esta convención sigue viva y cada vez con más fuerza, como lo demuestran los diversos mecanismos que actualmente son utilizados ampliamente para el cumplimiento de la misma: como son: "Ios informes periódicos que el Estado presenta y sobre los que el Comité se pronuncia; el sometimiento a su Protocolo Facultativo a través del cual el Comité conoce de casos individuales; y, la incorporación de sus estándares tanto a en la justicia ordinaria como la constitucional" (Huaita, 2017, pág. 51).

Conocer el proceso de ratificación de la CEDAW en nuestro país nos ha llevado a transitar las páginas de la historia e identificar el importante rol de célebres mujeres peruanas (algunas más conocidas que otras) presentes en diversos roles, todos ellos clave durante este proceso, tanto desde instituciones públicas como desde la sociedad civil.

La ratificación de esta Convención en el Perú se da a inicios de la década de los 80 , en un momento que, a nuestra manera de ver, es de transición entre dos generaciones de mujeres defensoras de sus derechos: una primera, que lucha en la primera mitad de siglo por el derecho al sufragio, que participa en la vida política nacional y cuyas integrantes son las primeras representantes en el Parlamento o asumen importantes responsabilidades públicas, entre las que identificamos a prestigiosas abogadas formadas en la PUCP; y una nueva generación de mujeres feministas que surge a fines de los 70 y que en los 80 se nutre de un núcleo de jóvenes abogadas, quienes van a encontrar en la CEDAW una fuente de inspiración y una ruta para la defensa de los derechos de las mujeres en el Perú. 
Antes de iniciar con el desarrollo quisieramos expresar un agradecimiento especial al Ministerio de Relaciones Exteriores por permitirnos consultar sus archivos y proporcionarnos copia de un material tanto inédito como interesante, especialmente para reconstruir la historia de este hito en la conquista de derechos de las mujeres peruanas.

\section{Antecedentes sobre la participación política de la mujer en el s. XX}

\subsection{La International Council of Women ICW y el Consejo Nacional de Mujeres en el Perú}

María Jesús Alvarado, quien es reconocida como la primera feminista peruana por ser la pionera de la lucha por el voto femenino, fundó en 1923 el Consejo Nacional de Mujeres del Perú. La fundación se da justamente durante la visita de Mrs. Carrie Chapman Catt, presidenta de la Alianza Internacional de las Mujeres por el Sufragio (Ministerio de la Mujer y Desarrollo Social, 2005, pág. 29).

Una vez fundado, el Consejo se orientó básicamente a la consecución del voto de la mujer, afiliándose al Consejo Internacional de Mujeres con sede en París, el mismo que fue creado en 1888 y que es reconocido como la organización internacional de mujeres más antigua de la historia, actualmente con estatus consultivo en las Naciones Unidas (International Council of Women, s.f.).

El Consejo ${ }^{(1)}$ tuvo entre sus miembros en esa primera mitad del siglo a lideresas como Matilde Pérez Palacio y su hermana Sara Pérez Palacio, entre otras célebres mujeres. Es importante destacar la trayectoria de Matilde Pérez Palacio (1913-1992), primera abogada PUCP (1941) (Ramos y Cuadros, 2019, pág. 79), quien impulsó desde el Movimiento Cívico Femenino la participación de la mujer en el sufragio y fue también una de las fundadoras de Acción Popular, así como la primera mujer que atestiguó en el Perú ante el Registro Civil haciendo uso de sus derechos de ciudadanía (Congreso de la República del Perú s.f.).

Sin duda, un primer logro de este movimiento fue el reconocimiento en la constitución de 1933 del derecho de la mujer al voto en el ámbito municipal, derecho que como se sabe no es ejercido sino hasta el año 1963.

2.2. Las pioneras en la participación política de la mujer peruana: las primeras diputadas, senadoras, alcaldesas Ya en la década del 50 , se da la primera participación formal de la mujer en la vida política del país. El año 1956 y luego de la dación de la Ley 12391, promulgada el 7 de setiembre de 1955, las mujeres ejercen su derecho de elegir y ser elegidas. Ese año, Matilde Pérez Palacio es elegida como diputada por el Frente Nacional de Juventudes (FNJD). Más tarde, continuando con su carrera política y ya con el partido político Acción Popular, del que fue fundadora, fue elegida senadora en 1962 y luego reelegida diputada en las elecciones de 1963.

En la década del 60 , otra de las participantes del Consejo Nacional de Mujeres, nombrada luego como Presidenta Honoraria Vitalicia, fue Anita Fernandini (1902-1982), quien fuera alcaldesa de Lima (1963-1964), ocupando por primera vez el sillón municipal una mujer. Por su parte María Vita de Alvarez (1917-2007) se incorpora al Consejo Nacional de Mujeres en 1967 y funda en 1969 el Secretariado Nacional de Instituciones privadas de Bienestar Social (SNIPBS), siendo su Secretaria General entre 1969-1971, para posteriormente ser regidora del Consejo Provincial de Lima entre 19761978 (Vita de Álvarez, 2008).

No fueron éstas las únicas mujeres que tuvieron roles relevantes en el espacio público, ya que en todos los grupos políticos contemporáneos se podían encontrar a mujeres líderes y militantes, así Sara Beatriz Guardia reconoce que:

"Al finalizar la década de 1950, el discurso de las mujeres peruanas había logrado un mayor radio de influencia. La obtención de derecho al sufragio y su participación política, no estaba ya circunscrita a un reducido grupo de vanguardia: El terreno estaba preparado para la irrupción de un discurso feminista mucho más enérgico, y al reto de nuevas formas de lucha en aras de sus derechos" (Guardia, 2002, pág. 188).

Eliana Villar (1994), por su parte, al analizar las trayectorias de estas mujeres describe sus diferentes derroteros:

"La diferencia entre las mujeres de AP y PAP e izquierda es que mientras las últimas -apristas e izquierdistas- se acercan a la política desde la práctica de sus familias, su participación en organizaciones sindicales y gremiales; las primeras son convocadas, "llamadas" por el partido previamente a un proceso electoral,

(1) De acuerdo a Vargas, luego que Alvarado se exilió en Argentina, el Consejo cayó en manos de mujeres mucho más conservadoras que pusieron énfasis en el rol doméstico de la mujer (Vargas, 2008, pág. 48). 
invitándolas a candidatear por Acción Popular" (Villar, 1994, pág. 89).

En el caso de Acción Popular, además, las mujeres invitadas por el partido son profesionales, de clase media o media alta y, además, se incorporan al partido cuando ya sus hijos estaban en la pubertad o adolescencia; es decir, liberadas de la carga doméstica y reproductiva dado que tenían hijos ya grandes (ídem). Por ello, estas mujeres, que habían luchado por el derecho al voto, se aproximaban a la política desde una visión más tradicional en relación con el rol de Estado y la protección de la familia. Ello se demuestra en el tipo de iniciativas que desarrollaron, como por ejemplo leyes en protección a las madres solteras y a la niñez en abandono, entre otras.

Durante la década de 1960, de acuerdo a Vargas,

“(..), comienzan a surgir un conjunto de instituciones y grupos interesados en abordar la problemática de la mujer, entre ellas, la Unión Popular de Mujeres del Perú, ligada a la Federación Democrática Internacional de Mujeres (Berlín Oriental), Centro Femenino Popular, Movimiento Promoción de la Mujer, Grupo de Trabajo Flora Tristán" (Vargas, 1992, pág. 31).

Este proceso democrático fue interrumpido en 1968 por el golpe de Velasco Alvarado, de manera tal que la década del 70 se inicia bajo un régimen militar.

\section{La década del 70 y la mujer}

La década del 70 es una década muy intensa, tanto en el contexto nacional como internacional, para sentar las bases en el reconocimiento de los derechos humanos de las mujeres y de una segunda ola del feminismo en el Perú.

Al inicio de esta década, Vargas (1985, pág. 132-133) reconoce hasta 3 diferentes tendencias en los grupos de mujeres:

- Una primera tendencia más conservadora, que propugna la asistencia a la mujer especialmente la de sectores populares, y busca desarrollar sus capacidades para que mejore el desempeño de sus roles tradicionales como madre y esposa.

- Una segunda tendencia más próxima a los partidos políticos que "(...) incentiva la participación de la mujer como un elemento de apoyo en las luchas sociales; aspira dotar a las mujeres de una conciencia política que se limita a defender los proyectos de cambio existentes, cualquiera sea su carácter: reformistas o revolucionarios" (Vargas, 1985, pág. 133).

- Una tercera tendencia es la que se reivindica como feminista, y que desarrolla una agenda diferente como la protesta contra la utilización del cuerpo de la mujer por los medios de comunicación o en los concursos de belleza, entre otros.
Es esta última tendencia, que se va gestando en esta década, a la que se le va a reconocer como el segundo feminismo. En esa línea de pensamiento concordamos con lo afirmado por Barrientos y Muñoz:

"El segundo feminismo peruano del siglo $X X$ toma fuerza gracias a la convergencia de dos factores políticos, uno interno - las reformas progresistas del gobierno militar peruano de Velasco Alvarado entre 1968 y 1976 - y otro externo, la realización de la Conferencia Mundial sobre la Mujer (1975), el Decenio de la Mujer (1975-1985) y el apoyo de la cooperación internacional a estas causas" (Barrientos \& Muñoz, 2014, pág. 640).

\subsection{Contexto internacional: La década de} la Mujer de Naciones Unidas 1975-1985

En 1947, poco después de la creación de las Naciones Unidas, se reúnen 15 mujeres representantes de los Estados parte constituyendo la Comisión de la Condición Jurídica y Social de la Mujer (CSW). Como parte de su labor logran incorporar en la Declaración de los Derechos Humanos un lenguaje más inclusivo (ej.: "humanidad" en lugar de "los hombres"). Así entre 1947 y 1962, su labor se centró en desarrollar un marco jurídico, a través de convenciones internacionales, que disminuyeran el impacto discriminatorio de las leyes sobre las mujeres. En 1963, ante esta enorme tarea, la CSW solicita a la asamblea que se apruebe una "Declaración sobre la eliminación de la discriminación contra la mujer", la que efectivamente se aprueba en 1967 y que es el antecedente directo del desarrollo de la CEDAW, cuya redacción también estuvo a cargo de esta Comisión.

A la par del surgimiento de movimientos de "liberalización de la mujer" o feministas, en la década del 70, especialmente en Estados Unidos y Europa, en 1972 la CSW recomendó que el año 1975 fuera declarado "Año internacional de la mujer". Así, Naciones Unidas identifica lo relacionado con la mujer como un área problemática, lanzando efectivamente el año 1975 como el año internacional de la mujer, y convocando para una conferencia mundial en México. El impacto del análisis de la problemática de la mujer en esta conferencia fue tal (Portocarrero, 1990, pág. 40 y sgts.), que del "Año de la mujer" se 
pasó a la "Década de la mujer", convirtiéndose la conferencia de México en la I Conferencia de la Mujer, planificándose otra al cierre de la década en Nairobi (1985) y pasando por una intermedia de evaluación en Copenhague (1980). Es en este contexto que en el año 1979 se aprueba la CEDAW en el marco de Naciones Unidas.

\subsection{El velasquismo y su propuesta de revalorización de la mujer} En el Perú, la década de la mujer coincide con el Velasquismo. En estos años de acuerdo a Barrientos y Muñoz:

\begin{abstract}
"se presenta una confluencia entre la agenda del Estado respecto al posicionamiento de la mujer en la esfera pública y la respuesta a las demandas de participación pública de la mujer por parte del movimiento de mujeres. Es así que se crea el Consejo Nacional de Mujeres del Perú (1971), la Comisión Nacional de la Mujer Peruana-CONAMUP (1974) y el Comité Técnico de Revaloración de la Mujer - COTREM (1972)" (2014, pág. 640).

De estas instituciones, es el CONAMUP el que al decir de Vargas "acoge en su seno a un conjunto de mujeres progresistas y democráticas que se interesan genuinamente por la situación de la mujer" (Vargas, 1985, pág. 132). Y en su seno se formaron Comisiones Especializadas para el estudio de los problemas más urgentes de la mujer en el Perú (Barboza,

- Comisión sobre la Condición Jurídica y Social de la Mujer

- Comisión sobre el Problema de la Prostitución

- Comisión sobre los Medios de Comunicación y la Mujer

- Comisión sobre la Mujer, Empleo y Población

- Comisión de Asuntos Internacionales
\end{abstract} 2013, pág. 72):

Es así que en 1975 se publica un documento de trabajo denominado "La problemática de la Mujer en el Perú", el mismo que fue preparado por Hilda Araujo, Dora Beuzeville y Mario Zolezzi, en su calidad de integrantes de la Secretaría Técnica para la Delegación Peruana a la Conferencia Mundial del Año Internacional de la Mujer, en el marco de la CONAMUP (Barboza, 2013, pág. 73).

De manera paralela, desde la sociedad civil se van organizando algunos grupos como el movimiento "Promoción de la Mujer" (1970), Acción para la Liberación de la Mujer en el Perú (ALIMUPER 1973) y el Grupo de Trabajo "Flora Tristán" (1973) (Olea, 2007).

En materia de tratados de derechos humanos, y acorde con sus postulados es importante destacar que durante el gobierno de Velasco se suscriben tanto la Convención para la eliminación de la discriminación racial (1971), como la Convención sobre Derechos Políticos de la Mujer de Naciones Unidas (1975).

\subsection{Morales Bermúdez y la transición democrática}

En agosto de 1975, se inicia la segunda fase del gobierno militar, esta vez al mando de Morales Bermúdez, que se caracteriza por el desmontaje progresivo de las políticas implementadas por
Velasco y la convocatoria a elecciones generales para la conformación de una Asamblea Constituyente.

El desmontaje de las políticas velasquistas afecta a la CONAMUP, la que es disuelta; sin embargo, "(...) algunas de sus integrantes lograron mantenerse organizadas en diferentes instituciones de mujeres, acercándose algunas de ellas a posiciones feministas (...)" (Vargas, 1985, pág. 132), reforzándose así las organizaciones de sociedad civil.

El 28 de julio de 1978 se instala la Asamblea Constituyente, con sólo 2 mujeres de 100 representantes electos y con una importante participación de representantes de izquierda (30\%), del APRA (35\%) y del PPC (26\%). En octubre de ese año, surge quizás la primera demanda formal del llamado segundo feminismo a una instancia democrática: ALIMUPER solicita la legalización del aborto voluntario a la Asamblea Constituyente (Barboza, 2013, pág. 47).

En este contexto de apertura democrática, que el gobierno militar el año 1978 decide suscribir 2 tratados de derechos humanos del Sistema de Naciones Unidas de absoluta relevancia: el Pacto Internacional de los Derechos Civiles y Políticos (PIDCP), así como el de los Derechos Económicos Sociales y Culturales (PIDESC), los mismos que habían estado abiertos a la firma de los Estados partes desde 1966. La asamblea constituyente entonces decide ratificar los mismos al año siguiente (1979), con lo cual son incorporados al marco normativo peruano.

La Constitución peruana de 1979 se caracteriza, a diferencia de las constituciones anteriores, por estar referida no sólo a la estructura del Estado, sino por contener una primera parte enfocada a los derechos de las personas, que es desarrollada largamente en 8 capítulos. En materia de derechos de las mujeres, la incorporación del principio de igualdad y no discriminación en razón de sexo, con una formulación que no deja dudas sobre el reconocimiento de los derechos de las mujeres, es el hito más importante de la década.

"Artículo 2. Toda persona tiene derecho:

2.- A la igualdad ante la ley, sin discriminación alguna por razón de sexo, raza, religión, 
opinión e idioma. El varón y la mujer tienen iguales oportunidades y responsabilidades. La ley reconoce a la mujer derechos no menores que al varón".

Esta aspiración será pues el paradigma de la lucha por los derechos de las mujeres de la siguiente década.

\subsection{La izquierda, los derechos de los grupos sociales más desventajados y las mujeres}

De manera paralela, las organizaciones de izquierda sufren cambios importantes en la década del 70 . Algunos de los grupos apoyan al gobierno de Velasco mientras que otros están más bien en agendas reivindicativas y en la defensa de los derechos de diferentes grupos sociales más desventajados en nuestra sociedad.

En el año 1971, por ejemplo, se fractura la Democracia Cristiana, y varios de sus militantes de tendencia de izquierda salen de sus filas. En este grupo encontramos por ejemplo a Rafael Roncagliolo, Henry Pease, Enrique Bernales, José María Salcedo, Manuel Benza Pflücker, María Luisa de Benzza, Alfredo Filomeno, entre otros (Adrianzén, 2011, pág. 318). Algunos de ellos, a título personal apoyan al gobierno de Velasco, y luego del golpe de Morales Bermúdez, en el año 1976 parte de este grupo funda el Partido Socialista Revolucionario (PSR). Justamente uno de sus líderes tendrá un rol relevante en la materia que nos ocupa.

En esta década se abre una amplia paleta de partidos de izquierda, en donde se encuentra militancia de mujeres y varones. Al decir de Vargas: "(...) muchas mujeres de diferentes sectores sociales, especialmente de clase media, sintieron que una vía para rebelarse y rechazar los estereotipos en los que estaban inmersas era unirse a los partidos políticos, particularmente los de izquierda" (2008, pág. 50). Sin embargo, muchas no encontraron ahí atención a sus demandas ni oportunidad para su desarrollo, y es así que, a finales de la década, se forman dos organizaciones feministas que se nutren de mujeres desencantadas de los partidos de izquierda: el Movimiento Manuela Ramos (1978) y el Centro Flora Tristán (1979) (López, 2017, pág. 121 - 157).

\section{Los 80 y el proceso de ratificación de la CEDAW}

Ya con una nueva Constitución se inicia el proceso electoral para las elecciones del nuevo gobierno que entraría en funciones en julio de 1980. Las elecciones las gana Acción Popular, con Fernando Belaúnde a la cabeza, el mismo que había sido derrocado por la cúpula militar el año 68. Muchos de sus líderes hombres y mujeres vuelven entonces a ocupar la escena pública, pero el Perú había cambiado. El Congreso elegido es bicameral, siendo electas 2 senadoras de 60 (3\%) y 13 diputadas (6\%) de 180 (Ministerio de la Mujer y Desarrollo Social, 2005).
En este marco se dan dos fenómenos: (i) el inicio de la lucha armada de parte del PCSendero Luminoso en abril de 1980 y (ii) el surgimiento de Izquierda Unida como alianza electoral que logra colocar representantes en el Parlamento peruano y más tarde en 1983 gana la Alcaldía de Lima con Alfonso Barrantes a la cabeza.

\subsection{El contexto de los derechos humanos}

En el Perú cuando se habla de derechos humanos en la década del 80 , casi todas las referencias las vamos a encontrar en relación con la violación de éstos y no así con su afirmación positiva. La izquierda peruana al mismo tiempo que en la década anterior había tratado de asumir la defensa de los derechos de los grupos sociales con mayores carencias en nuestro país, y que tiene una importante participación en el sistema democrático recién instaurado, no supo deslindar desde el comienzo con la propuesta cruenta de PCSendero Luminoso, que se mostró desde sus inicios como un grupo violentista sin respeto alguno por los derechos de los peruanos y peruanas.

Dado el contexto nacional, la lucha por los derechos de las mujeres pasó a verse como una demanda irrelevante y hasta "burguesa", como lo señala Victoria Villanueva, los partidos, específicamente los de izquierda, no consideraban en sus agendas las demandas feministas de las mujeres adscritas a ellos, por lo que, en 1982, "un número considerable de mujeres salimos de los partidos sin discusión, sin debate ideológico, sin pena ni gloria" (2004, pág. 30).

Quizás por ello, en estos años no hay mayor referencia sobre la agenda positiva de los derechos humanos, entre la que se encuentra la firma y ratificación de la Convención para la eliminación de toda forma de discriminación contra la mujer, proceso que se da entre mayo de 1981 y setiembre de 1982.

Curiosamente, este hito en la historia de los derechos de las mujeres no ha sido reivindicado ni por los grupos de mujeres, ni por los partidos de izquierda, ni siquiera por el gobierno que lo suscribió. Así lo demuestran, por ejemplo, los libros testimoniales de este 
período de la historia. Desde el movimiento feminista, los diferentes testimonios de mujeres de la época (Orvig, 2015; Vargas,1985, 2008; Olea, 2007; Villanueva, 1995 y 2004; Gissela Pisconti, 2017) no hacen referencia alguna a este episodio. Tampoco lo hacen los dirigentes de izquierda, que sólo hablan de derechos humanos en función del conflicto armado interno provocado por PC-SL y tampoco se consigna en el libro publicado por Servicios Populares "que fue un núcleo de asesoría del Parlamento, y publicó el balance sistematizado de la agenda de IU en el Parlamento", de acuerdo al testimonio de Mocha García Naranjo (Adrianzén, 2011, pág. 341). Ni siquiera lo hace el propio Bernales (2018) en su libro autobiográfico.

En esa misma línea, el hecho no es revelado por notas periodísticas de la época: no aparece cobertura alguna en diarios como El Comercio, Correo y La Crónica, ni en La Marka (el diario de izquierda de esos años). Solo El Peruano publicó la Resolución Legislativa que la aprueba el 5 de junio de 1982. Sin embargo, los documentos oficiales nos cuentan la historia, la misma que creemos importante compartir.

\subsection{El contexto internacional y la CEDAW}

En 1980 se da la II Conferencia de la Mujer en Copenhague, y en ella se hace un llamado a todos los Estados para la firma y ratificación de la CEDAW, que ya había sido aprobada y abierta para su firma, desde fines de la década anterior.

\subsection{El proceso y los actores públicos y privados}

De acuerdo a la Constitución de 1979 (artículo 102), todo tratado internacional debía ser aprobado por el Congreso antes de su ratificación por el presidente de la república. Por ello, revisaremos la actuación de ambos poderes del Estado.

\subsubsection{Actores en el Poder Legislativo}

A pesar de la presencia de dos mujeres en el senado, Rosa Estrada de Alba de Acción Popular y Juana Castro Zegarra del Partido Aprista Peruano, es el entonces senador de la república por la Unidad de Izquierda, Enrique Bernales(2), quien presenta la iniciativa en el Senado para que el Ministro de Relaciones Exteriores proponga al Congreso la aprobación de la CEDAW. La fecha de dicha solicitud ante el Senado es el 21 de mayo de 1981, como consta del Oficio $N^{\circ}$ 538/2.L.O.DL. Para ese momento, la CEDAW ya había sido ratificada por la mayoría de países de América Latina, y en Sudamérica sólo restaban Paraguay y Perú, por lo que había una cierta presión internacional sobre el país para que se proceda a su ratificación. La solicitud del senador Bernales coincide entonces con las vísperas de una Reunión de expertos de países No alineados sobre el Rol de la Mujer en el Desarrollo, que se celebraba en la ciudad de La Habana, Cuba, del 22 al 27 de mayo (Oficio $\left.\mathrm{N}^{\circ} 7-1-\mathrm{B} / 235\right)$.

\subsubsection{Actores en el Poder Ejecutivo}

Con Oficio $\mathrm{N}^{\circ} 7-1-\mathrm{B} / 208$ de 28 de abril de 1981, el entonces representante permanente del Perú ante las Naciones Unidas, embajador Juan José Calle remite al ministro de Relaciones Exteriores, Javier Arias Stella, una copia certificada del texto de la CEDAW, advirtiendo que una copia de la misma le había sido remitido a Cancillería 1 año antes, el 11 de junio de 1980; es decir en las postrimerías del Gobierno de Morales Bermúdez.

Con fecha 8 de mayo, el mismo embajador oficia a Cancillería informándole de la próxima reunión en La Habana y solicitando la conformación de la delegación oficial que asistiría a dicha reunión. Es en este marco, que el Senado solicita a Cancillería que proponga la aprobación de la CEDAW.

En Cancillería, una vez recibida la propuesta del Senado, mediante Memorándum 98, del 2 de junio de 1981, María Victoria Salazar Castellanos, directora de Organismos y Conferencias Internacionales, expresa "la conveniencia de la firma de la citada Convención, teniendo en cuenta que los postulados de la misma armonizan con el artículo 2, inc. 2 de la Carta Fundamental que nos rige".

En base a ello, por Resolución Suprema $N^{\circ} 425$ del 09 de julio de 1981, se autoriza a la misión de NN. UU. a proceder a la firma de la CEDAW, y es así que con fecha 23 de julio de 1981, Hernán Couturier Mariátegui, ministro consejero, encargado de negocios (a.i.) procede a la suscripción de la Convención, lo que da cuenta a Cancillería con Oficio $N^{\circ} 7$ 1-B/356 de 24 de julio de 1981.

Hasta ahí, el primer paso se había cumplido, lo siguiente sería lograr su ratificación definitiva. Para ello Cancillería, a través de Hernán Ramírez

(2) Enrique Bernales Ballesteros (Senador 1980-1992), era abogado y profesor de la Pontificia Universidad Católica del Perú. Doctor en Derecho por la Universidad de Grenoble e interesado en la dinámica internacional, siendo "Relator de especial para el Mercenarismo de la Comisión de Derechos Humanos de Naciones Unidas (1987-2004). Años después escribe 2 artículos respecto de esta convención: La Protección Internacional de los derechos humanos de las mujeres (1996) y Derechos Humanos de las mujeres. Aportes y reflexiones (1998). Ambos publicados por el Movimiento Manuela Ramos como parte del Curso Anual sobre Derechos Humanos de las Mujeres que realizaba en los 90. 
Lituma, ministro consejero, como es usual en estos casos, solicita opinión a diferentes instituciones públicas y privadas sobre la conveniencia de suscribir tal tratado. Veamos en detalle el proceso.

Siendo el Poder Ejecutivo liderado por el gobierno de Acción Popular, encontramos esta vez a personajes vinculados a esta agrupación política dando opinión relevante sobre este tratado que reivindica los derechos de las mujeres.

Un primer análisis es sobre las instituciones a las que se les pide opinión. Dada la amplitud de esferas abordadas por la CEDAW, y atendiendo a que en el momento no existía un mecanismo específico dedicado a la problemática de la mujer, es la Cancillería quien lidera este proceso y emite sendos oficios a instituciones donde se solicita opiniones a diversas instituciones del sector público, como se aprecia en el siguiente cuadro:

\begin{tabular}{|c|c|c|c|c|}
\hline $\begin{array}{l}\text { Entidad del Sector } \\
\text { Público }\end{array}$ & Responsable & Cargo & Documento & Fecha \\
\hline Ministerio de Educación & $\begin{array}{l}\text { José Benavides } \\
\text { Muñoz }\end{array}$ & $\begin{array}{l}\text { Ministro de } \\
\text { Educación }\end{array}$ & $\begin{array}{l}\text { Oficio } \\
\text { N²}^{\circ} 639 \mathrm{ME} / \mathrm{OAI}- \\
\text { Ol-81 }\end{array}$ & 23.10.1981 \\
\hline Ministerio de Trabajo & $\begin{array}{l}\text { Alfonso Grados } \\
\text { Bertorini }\end{array}$ & $\begin{array}{l}\text { Ministro de } \\
\text { Trabajo }\end{array}$ & $\begin{array}{l}\text { Oficio N447/81/ } \\
\text { TR }\end{array}$ & 21.10.1981 \\
\hline $\begin{array}{l}\text { Instituto Nacional de } \\
\text { Planificación - INP }\end{array}$ & $\begin{array}{l}\text { Carlos Pestana } \\
\text { Zevallos }\end{array}$ & Jefe & $\begin{array}{l}\text { Oficio N 097-81/ } \\
\text { INP-DGPS-DAS }\end{array}$ & 02.11.1981 \\
\hline $\begin{array}{l}\text { Instituto Peruano de Se- } \\
\text { guridad Social - IPSS }\end{array}$ & $\begin{array}{l}\text { Octavio Mongrut } \\
\text { Muñoz }\end{array}$ & $\begin{array}{l}\text { Presidente } \\
\text { Ejecutivo }\end{array}$ & $\begin{array}{l}\text { Oficio N¹194- } \\
\text { AT-PE-IPSS-81 }\end{array}$ & 30.11 .1981 \\
\hline $\begin{array}{l}\text { Instituto Nacional de } \\
\text { Bienestar Familiar - } \\
\text { Inabif }\end{array}$ & $\begin{array}{l}\text { Matilde Pérez } \\
\text { Palacio Carranza }\end{array}$ & Jefe & $\begin{array}{l}\text { Oficio No 102- } \\
81 / \mathrm{J}\end{array}$ & 29.09 .1981 \\
\hline
\end{tabular}

En general todas las opiniones que se recogen del Poder Ejecutivo se alinean al marco de la Constitución de 1979, y por tanto emiten una opinión positiva respecto del tratado. Sin embargo, de las varias opiniones emitidas y firmadas por ministros de Estado y altos funcionarios estatales, nos detendremos en el análisis de la opinión emitida por el Inabif por dos razones: es la que desarrolla más argumentos en su informe, y la única emitida por una alta funcionaria de Estado.

En efecto, es ahí donde nos reencontramos con Matilde Pérez Palacio, la exluchadora por el voto femenino y exdiputada de Acción Popular, ahora se encuentra dirigiendo una importante institución del sector público, institución que además corresponde a su visión de asistencia y apoyo a las mujeres abandonadas o en sus roles tradicionales de esposa y madre. Pérez Palacio fue directora del Instituto de Bienestar Infantil (Inabif) durante todo el período de gobierno de Acción Popular (1981-1985) y es a ella a quien la historia pone en sus manos la oportunidad de dar una opinión favorable a la ratificación de la CEDAW en nuestro país.

La opinión emitida por el Inabif es elaborada por Clara Córdova Rivera (abogada PUCP), a la sazón directora encargada de la Oficina de Asesoría Jurídica del Inabif. La doctora Córdova además de opinar favorablemente por la ratificación de tan importante Convención, en su análisis tiene una lectura bastante crítica en relación a los avances que sobre los derechos de la mujer. En primer lugar, critica lo poco hecho durante el gobierno militar, así menciona que:

"Lo importante es que se suscriba y se ratifique, ya que, durante el Decenio de la Mujer declarado por las Naciones Unidas, en el Perú el Derecho Positivo, al parecer no ha incorporado leyes que directamente o indirectamente concluyan con la discriminación por razón de sexos" (Oficio 102-81/J).

De otro lado, la opinión también deja traslucir la aspiración de las mujeres de ocupar cargos en la esfera pública en igualdad de condiciones que los varones; así, a pesar de la opinión favorable para su pronta ratificación, se propone una precisión en la Convención, en el sentido que "en la Parte II Artículo 70 inciso b) debe completarse. "... y ejercer todas las funciones públicas en todos los planos gubernamentales, como los cargos de Ministros de Estado, Magistrados del Poder Judicial, en todas sus Instancias, en igualdad de oportunidades con los hombres" (subrayado en el original. Oficio $\mathrm{N}^{\circ}$ 102-81/J). Inmediatamente después desliza una crítica al gobierno de turno: "Creemos que expresamente se deben referir a esos cargos públicos porque en el caso peruano no han sido designados Ministros; vocales de la Corte (sic) Suprema mujeres, y entre los Magistrados actuales en las Instancia Primera y Segunda, el porcentaje de mujeres es diminuto, en Lima, frente al de varones" (Subrayado en el original Oficio 102-81/J).

Y no sólo eso, la opinión recogida y trasladada formalmente a Cancillería por Matilde Pérez Palacio expresa:

"Personalmente consideramos que paralelo a la dación de leyes que establezcan la igualdad en el derecho positivo, debe señalarse la igualdad de oportunidades que debe estar en el fondo de la igualdad jurídica porque sinó [sic] son lo que hasta ahora "declaraciones líricas" (Subrayado en el original. Oficio 102-81/J).

Es decir, la ratificación de la CEDAW es una oportunidad para que estas mujeres 
expresen sus aspiraciones de igualdad de oportunidades y su relegación en la participación en la esfera pública, tanto en el Poder Ejecutivo como en el Poder Judicial, y así lo expresan claramente en la documentación oficial bajo análisis.

\subsubsection{Actores desde la Sociedad Civil}

Cancillería solicita también opiniones a instituciones de Sociedad Civil, y aquí nos encontramos nuevamente a las mujeres del histórico Consejo Nacional de Mujeres, que en ese momento de sus vidas lideran instituciones de sociedad civil, que en la década de los 80 gozan del reconocimiento estatal. Mientras que las novísimas organizaciones feministas aún no han ocupado el espacio público formal, y peor aún muchas de sus militantes están en un proceso de distanciamiento con sus agrupaciones políticas, todo lo cual explica porque a pesar de su agenda ampliamente coincidente con la propuesta de la CEDAW, no se constituyen como actoras relevantes en este proceso.

Así pues, las opiniones recabadas desde la sociedad civil para la ratificación de la CEDAW provienen de:

\begin{tabular}{|c|c|c|c|c|}
\hline $\begin{array}{l}\text { Entidad de la } \\
\text { Sociedad Civil }\end{array}$ & Responsable & Cargo & $\begin{array}{l}\text { Docu- } \\
\text { mento }\end{array}$ & Fecha \\
\hline $\begin{array}{l}\text { Consejo Nacional } \\
\text { de Mujeres del Perú }\end{array}$ & $\begin{array}{l}\text { María Vita de } \\
\text { Alvarez }\end{array}$ & Presidenta & $\begin{array}{l}\text { Carta } \\
s / n\end{array}$ & 03.09.1981 \\
\hline \multirow{2}{*}{$\begin{array}{l}\text { Secretariado } \\
\text { Nacional de Institu- } \\
\text { ciones Privadas de } \\
\text { Bienestar Social. } \\
\text { SNIPBS }\end{array}$} & $\begin{array}{l}\text { Sara M. Pérez } \\
\text { Palacio de Ruiz } \\
\text { Eldredge }\end{array}$ & $\begin{array}{l}\text { Secretaria } \\
\text { General }\end{array}$ & \multirow{2}{*}{$\begin{array}{l}\text { Carta } \\
s / n\end{array}$} & \multirow{2}{*}{11.09 .1981} \\
\hline & $\begin{array}{l}\text { Ana Medina de } \\
\text { Díaz Rodríguez }\end{array}$ & $\begin{array}{l}\text { Vocal de } \\
\text { Relaciones } \\
\text { Públicas }\end{array}$ & & \\
\hline
\end{tabular}

De un lado, es el propio Consejo que emite una opinión positiva para la ratificación de la CEDAW, esta vez liderado por María Vita de Álvarez. La opinión del Consejo es positiva en relación con la ratificación de la CEDAW; sin embargo, también expresa algunas recomendaciones que guardan relación con la posición conservadora de las mujeres que formaban parte del mismo.

De acuerdo a la carta remitida a Cancillería, la opinión es emitida después de una sesión de la Comisión de Legislación del Consejo, del que formaban parte: "Las Doctoras, Gabriela Araníbar Fernández Dávila, Carmen Rodríguez de Muñoz, Olga Paredes Lañas de De Olarte, Angélica Alvarez de La Cruz, Elsa Roca de Salonem y Esther Silva de Ghersi así como la Dra. Eva María Robertson de Otayza, miembro de la Comisión de Relaciones Internacionales y Paz" (Carta de 03.09.1981). De este grupo, 3 de ellas eran abogadas formadas en la PUCP: Olga Paredes Lañas de De Olarte, Esther Silva de Ghersi y Eva María Robertson de Otayza.

De las 4 recomendaciones que el Consejo desarrolla, la primera está referida a precisar que la Constitución del Perú (de 1979), ya consagra el principio de igualdad y no discriminación por sexo, mientras que las otras 3 están referidas al ámbito de los derechos reproductivos, pero dejando clara su visión provida. Así, el Consejo recomienda que en el artículo 10, inciso h) de la Convención se agregue el concepto de "paternidad responsable" y "planificación de la familia"; que en el artículo 14, inciso d) se agregue el concepto de "educación familiar y paternidad responsable"; y que en el artículo 11, inciso f):

"El país debe aclarar que:

El Perú entiende el concepto "función de reproducción" como el derecho a la protección de la maternidad y de los seres que están por nacer" (Carta de 03.09.1981).

Esta carta contribuye a mostrar la distancia en las posiciones de entidades de la sociedad civil que desarrollan luchas por los derechos de la mujer. Por un lado, el Consejo Nacional de Mujeres que fue en su origen revolucionario y sufragista, y que luego de varias décadas se muestra como una institución ya reconocida con un estatus consultivo para el gobierno de turno y con una posición conservadora pro vida. Por otro lado, la nueva ola feminista con sus organizaciones recién establecidas, reivindican una posición pro-choice, pero aún no logran reconocimiento por parte del gobierno, y plantean sus demandas desde las calles.

La segunda opinión, desde la sociedad civil se le solicita a la secretaria general de Instituciones de Bienestar Social, que había sido fundado por María Vita de Álvarez, y que en la fecha está siendo liderada por otra compañera del Consejo Nacional de Mujeres, Sara Pérez Palacio.

En la carta dirigida a Cancillería, la Sra. Sara Pérez Palacio da cuenta que para emitir su opinión institucional se ha reunido el Comité de Asesoría Legal, conformado por la abogadas: "(..) señoras Carmen Rodríguez de Muñoz, Olga Paredes Lañas de De Olarte, Raquel Beaumont de Maceda y señorita Carmen Meza Inga", todas ellas abogadas PUCP, manifestando que el mencionado comité se ha pronunciado "sobre la conveniencia de solicitar al Gobierno Constitucional se ratifique la Convención sobre la Eliminación de todas las formas de Discriminación de la Mujer, a fin de que la 
mujer goce lo más pronto posible del reconocimiento de sus derechos" (Carta de 11.09.1981). Para ello acompaña además la exposición fundamentada de tal solicitud.

Esta exposición es preparada por Olga Paredes Lañas de De Olarte, jurista peruana, quien además de ser miembro del Consejo Nacional de Mujeres fue presidenta de la Federación de Abogadas del Perú y presidenta de la Unión de Mujeres Americanas (Torres Muga, 2012). La doctora Paredes, luego de manifestar que "la Convención en sus 30 artículos está de acuerdo a nuestras inquietudes, que es una respuesta a la preocupación de las Naciones Unidas por 'La situación de la Mujer'" (Carta de 11.09.1981), hace alusión a los distintos esfuerzos impulsados desde el año 1942 en Naciones Unidas hasta la Conferencia de México en 1975. Asimismo, en su opinión manifiesta que la CEDAW:

“(...) compromete a los Estados-Partes a consagrar en sus constituciones nacionales y en cualquier otra legislación el principio de igualdad, prohibiendo toda discriminación; recomienda a los Estados partes modificar los patrones socio-culturales de conducta de hombres y mujeres a fin de alcanzar la eliminación de prejuicios y prácticas que estén basados en la idea de inferioridad o superioridad de cualquiera de "los sexos o en funciones estereotipadas [sic] de hombres y mujeres" (Carta de 11.09.1981).

Asimismo, y tratándose de una institución dedicada al bienestar familiar, releva las obligaciones derivadas de esta Convención en este ámbito, así reconoce que la CEDAW:

"Garantiza la Educación Familiar, el respeto por la maternidad como funci6n social y la responsabilidad común de hombres y mujeres en la educación y desarrollo de sus hijos. En cuanto al trabajo establece iguales oportunidades de empleo, derecho a igual remuneración, etc." (Carta de 11.09.1981).

Finalmente concluye que se debe recomendar al gobierno peruano ratificar la Convención.

El oficio de la SNIPBS además de la opinión central desarrollada por la doctora Olga Paredes, acompaña en una página otras opiniones, entre las que se encuentran las siguientes:

"En nuestro país diferentes comisiones de juristas se encuentran estudiando las reformas de los Códigos y Leyes, a la luz de la Constitución de 1979, que consagra la igualdad de derechos entre las mujeres y los varones' Por eso el SECRETARIADO NACIONAL DE INSTITUCIONES PRIVADAS DE BIENESTAR SOCIAL considera que la ratificación de 'la Convención significaría un paso más en el propósito de re-elaborar el Derecho de acuerdo a los elementales postulados de la igualdad, principio básico de la justicia" (Carta de 11.09.1981).

"Que se adecuen los Códigos a la Constitución" (Carta de 11.09.1981).

"Que el Parlamento recomiende lo más pronto la adecuación de todos los instrumentos legales" (Carta de 11.09.1981).
Así pues, queda claro que las mujeres de la SNIPBS estaban al tanto de la necesidad de alinear la legislación interna a la carta constitucional de 1979, que había plasmado el principio de igualdad y no discriminación por sexo, y urgían al gobierno a proceder con las modificaciones legales pertinentes, siendo el proceso de ratificación de la CEDAW una oportunidad adicional de presión por estas reformas.

Finalmente, el ministro de Relaciones Exteriores envía al Congreso, el Oficio RE (TRA) N³-0-Y/04 de 31. 03.1982 con las opiniones a favor de la ratificación del tratado de todas las instituciones antes referidas, para que el Congreso de la República, en virtud de sus atribuciones, la apruebe formalmente. El 24 de mayo de 1982, las Comisiones de Relaciones Exteriores tanto del Senado como de la cámara de diputados acuerdan su aprobación, dándose la Resolución Legislativa $N^{\circ} 23432$, publicada el 05.06.1982, por la cual el Parlamento aprueba la CEDAW, ratificada luego formalmente por el Estado Peruano el 13 de septiembre de 1982.

\section{Importancia de la ratificación para la defensa y conquista de nuevos derechos}

De acuerdo al artículo 105 de la Constitución de 1979, los preceptos contenidos en los tratados relativos a derechos humanos tenían jerarquía constitucional, es decir, no podían ser derogados ni modificados, salvo que a su vez se modificase la Constitución. De acuerdo a ello, siendo la CEDAW un tratado de derechos humanos, sus preceptos eran incorporados al bloque constitucional y, por tanto, deberían ser respetados por todas las instancias del Estado peruano. Es justamente la exigencia de este compromiso una de las agendas más importantes del movimiento feminista que se desarrolla en los siguientes años.

Así pues, la ratificación de la CEDAW es probablemente el último acto relativo a la conquista de los derechos de las mujeres, de una generación sufragista que había pasado de la demanda reivindicativa de la primera mitad del S. XX, a ejercer cargos públicos en la segunda mitad del siglo, terminando 
sus últimos años dirigiendo instituciones públicas y privadas de gran importancia, pero que aún correspondían a una visión asistencialista respecto del rol de la mujer en nuestra sociedad. Fueron ellas quienes con su opinión positiva abrieron las puertas a la CEDAW y nos dieron la oportunidad para el despliegue de toda su potencialidad que es descubierta por las abogadas feministas de la década del 80 , pero esa ya es otra historia.

\section{Conclusiones}

- La ratificación de la CEDAW, que se da a inicios de los 80, se enmarca en un proceso de transición, no sólo política sino de dos generaciones de mujeres: las que lucharon por el derecho al voto en la primera mitad del s. XX y las de la segunda ola del movimiento feminista cuya demanda estará más centrada en torno al cuerpo de la mujer.

- En el primer grupo encontramos a mujeres profesionales que luego de la conquista del voto han sido llamadas a participar en la vida política, como Matilde Pérez Palacio que fue la primera abogada PUCP y luego diputada por Acción Popular, y otras que han fundado organizaciones no gubernamentales de protección la infancia y a la madre abandonada como María Vita de Álvarez. Todas ellas fueron profesionales destacadas vinculadas siempre al Consejo Nacional de Mujeres como Sara Pérez Palacio, Olga Paredes Lañas de De Olarte y muchas más.

- Son ellas a las que al inicio de la década de los 80 las encontramos liderando instituciones públicas (como Inabif) o de sociedad civil (como el Consejo Nacional de Mujeres del Perú), y desde ahí asumen la responsabilidad de opinar en favor de la ratificación de la CEDAW, pero ejerciendo también su derecho de crítica al gobierno de turno.

- El principio de igualdad por razón de sexo, establecido por la Constitución de 1979, es coincidente con la propuesta de la Convención, y por tanto facilita la opinión positiva de diversas entidades públicas.

- La presión internacional y el rol de Cancillería resultan claves para lograr este importante hito, ya que para el año 1982, sólo Perú y Paraguay en Sudamérica no habían procedido a su ratificación.

- Como parte de este proceso hemos visto como abogadas formadas en la PUCP se encuentra ubicadas tanto en el sector público como privado (como Matilde Pérez Palacio, Olga Paredes Lañas de De Olarte, Clara Córdova Rivera, Esther Silva de Ghersi, Eva María Robertson de Otayza Carmen Rodríguez de Muñoz, Raquel Beaumont de Maceda y Carmen Meza Inga) jugaron un importante rol, estando comprometidas desde muy temprano en la defensa de los derechos de las mujeres, y la ampliación de los marcos jurídicos para su protección.
- En las décadas siguientes es el movimiento feminista de segunda ola quien va a desplegar toda la potencialidad reivindicativa de la Convención.

\section{Referencias bibliográficas}

Adrianzén, Alberto (edit.) (2011). Apogeo y crisis de la izquierda peruana. Hablan sus protagonistas. Lima: Editorial de la Universidad Antonio Ruiz de Montoya.

Barboza, Marco (2013). La Liberación de la mujer en el Perú de los 70s: una perspectiva de género y estado. (Tesis de grado académico de Magister en Género, Sexualidad y Políticas Públicas). Universidad Nacional Mayor de San Marcos, Perú.

Barrientos, Violeta \& Muñoz, Fanni (2014). Un bosquejo del feminismo/s peruano/s: los múltiples desafíos. Estudios Feministas, 22 (2). Recuperado el 26 de octubre de 2018, de https://www.redalyc. org/pdf/381/38131661015.pdf

Bernales, Enrique (2018). 60 años en la PUCP. Una vida universitaria. Lima: Fondo editorial de la Pontificia Universidad Católica del Perú.

Carta del Consejo Nacional de Mujeres del Perú de 03.09.1981

Carta del Secretariado Nacional de Instituciones Privadas de Bienestar Social. SNIPBS de 11.09.1981

Cátedra UNESCO México (s.f.). ¿Qué es la CEDAW? Recuperado el 26 de octubre de 2018, de http://catedraunescodh.unam.mx/catedra/ mujeres3/CEDAW2/index2b9e.html?option=com content\&amp; view=article\&amp;id=1\&amp; $\mid$ temid $=\overline{2}$

Congreso de la República (s.f.). Primeras mujeres parlamentarias 1956 - 1962. Recuperado el 3 de octubre de 2018, de http://www.congreso.gob.pe/ primerasmujeresparlamentarias/Trayectoria/

Dictamen $N^{\circ} 382$ del 24 de mayo de 1982, con opinión positiva para la aprobación de la CEDAW de la Comisión de Relaciones Exteriores de la Cámara del Senado y de la Comisión de Relaciones Exteriores de la Cámara de Diputados.

Guardia, Sara (2002). Mujeres Peruanas. El otro lado de la historia (4ta ed.). Lima: CEMHAL.

Huaita Alegre, Marcela (2017). La CEDAW como marco de referencia de las Sentencias del Tribunal Constitucional peruano. Revista Peruana de Derecho Constitucional Mujer y Constitución, 10, pág. 23-52.

International Council of Women. (s.f.). History. Recuperado el 3 de octubre de 2018, de http:// www.icw-cif.com/01/03.php 
López, Fiorella (2017). El discurso sobre la emancipación de la mujer durante el conflicto armado interno en el Perú: memorias de las mujeres del PCP - Sendero Luminoso. Revista del Instituto Riva-Agüero, 2(1). Recuperado el 3 de octubre de 2018, de http://revistas.pucp.edu. pe/index.php/revistaira/article/view/15346/15803

Memorándum 98 del 2 de junio de 1981, de la Directora de Organismos y Conferencias Internacionales.

Ministerio de la Mujer y Desarrollo Social (2005). 50 años del voto femenino en el Perú. Historia y Realidad Actual. Lima: Ministerio de la Mujer y Desarrollo Social. Recuperado el 26 de octubre de 2018, de: https://www.mimp.gob.pe/webs/mimp/ sispod/pdf/89.pdf

Oficio N7-1-B/208 de 28 de abril de 1981, del Representante Permanente del Perú ante las Naciones Unidas.

Oficio $\mathrm{N}^{\circ} 7-1-\mathrm{B} / 235$ de 8 de mayo de 1981, del Representante Permanente del Perú ante las Naciones Unidas.

Oficio N 538/2.L.O.DL del 22 de mayo de 1981, del Senado de la República

Oficio N7-1-B/300 de 26 de junio de 1981, del Encargado de Negocios (a.i.)

Oficio $\mathrm{N}^{\circ} 7-1-\mathrm{B} / 356$ de 24 de julio de 1981, del Encargado de Negocios (a.i.)

Oficio $\mathrm{N}^{\circ} 102-81 / \mathrm{J}$, de 29.09.1981. Instituto Nacional de Bienestar Infantil.

Oficio $\mathrm{N}^{\circ} 447 / 81 / \mathrm{TR}$ de 21.10.1981, Ministerio de Trabajo.

Oficio $\mathrm{N}^{\circ} 2639 \mathrm{ME} / \mathrm{OAI}-\mathrm{Ol}-81$ de 23.10.1981, del Ministerio de Educación.

Oficio N097-81/INP-DGPS-DAS de 02.11.1981, Instituto Nacional de Planificación.

Oficio N¹194-AT-PE-IPSS-81 de 30.11.1981, Instituto Privado de Bienestar Social.

Oficio RE (TRA) N³-0-Y/04 de 31. 03.1982 del Ministro de Relaciones Exteriores.

Olea Mauleón, Cecilia (2007). La trayectoria del movimiento feminista en el Perú. Labrys, études féministes. Recuperado el 26 de octubre de 2018 , de https://www.labrys.net.br/labrys11/peru/olea.htm
Orvig, Helen (2004). También antes hubo algo. En G. Cevasco (edit.), 25 años de feminismo en el Perú: Historia, Conferencias y Perspectivas (pág 18-23). Lima: Centro de la Mujer Peruana Flora Tristán. Recuperado el 06 de octubre de 2018, de http://www2.congreso.gob.pe/sicr/ cendocbib/con4_uibd.nsf/C08CBB7DF991A3FF05257B1700675D74/ \$FILE/BVCI0003574.pdf

(2015). ¡Comprendí porqué éramos tantas! El despertar de las mujeres en el Perú. Lima: Fondo editorial de la UPCH.

Pisconti, Gissela (2017). Conquistando la diferencia. 16 años trabajando por la igualdad al interior de la CGTP. Lima: Biblioteca Nacional del Perú.

Portocarrero, Patricia (edit.) (1990). Mujer en el Desarrollo. Balance y propuestas. Lima: Centro de la Mujer Peruana Flora Tristán.

Ramos Nuñez, Carlos \& Cuadros Sánchez, Hans (2019). Crónicas de Claustro: Cien años de historia de la Facultad de Derecho de la PUCP. Lima: Fondo editorial de la PUCP.

Resolución Legislativa $N^{\circ} 23432$ por la cual el Congreso aprueba la CEDAW, publicada el 05/06/1982.

Sistema de Naciones Unidas de Panamá (s.f.). Convención sobre la eliminación de todas las formas de discriminación contra la mujer (CEDAW). Recuperado el 26 de octubre de 2018, de https://www. unicef.org/panama/spanish/MujeresCo_web.pdf

Vargas, Virginia (1985). Movimiento Feminista en el Perú: balance y perspectivas. Debates en Sociología, 10, pág. 121-146.

(1992). Cómo cambiar el mundo sin perdernos. El movimiento de Mujeres en el Perú y América Latina. Lima: Centro de la Mujer Peruana Flora Tristán.

(2004). Los feminismos peruanos: breve balance de tres décadas. En G. Cevasco (edit.), 25 años de feminismo en el Perú: Conferencias y Perspectivas (pág. 10-17). Lima: Centro de la Mujer Peruana Flora Tristán.

(2008). Feminismos en América Latina: su aporte a la política y a la democracia. Lima: Fondo Editorial de la Facultad de Ciencias Sociales.

Villanueva, Victoria (1995). Casi como jugando. Una historia a través de la capacitación. Lima: Movimiento Manuela Ramos.

(2004). Feminismo: una práctica de acción política. En G. Cevasco (edit.), 25 años de feminismo en el Perú. Conferencias y perspectivas (pág. 27-33). Lima: Centro de la Mujer Peruana Flora Tristán.

Villar Márquez, Eliana (1994). Por mérito propio: Mujer y política. Lima: Ediciones Flora Tristán.

Vita de Álvarez, María (18 de abril de 2008). Una voluntaria ejemplar. Consejo Nacional de Mujeres del Perú. Recuperado el 4 de octubre de 2018, de http://mariavitadealvarez.blogspot.com/2008/04/consejonacional-de-mujeres-del-per 18.html 